\title{
Foreign body ingestion in children
}

\author{
Selim Dereci ${ }^{1}$, Tuğba Koca ${ }^{1}$, Filiz Serdaroğlu², Mustafa Akçam ${ }^{1}$ \\ ${ }^{1}$ Department of Pediatrics, Division of Pediatric Gastroenterology, Hepatology and Nutrition, Süleyman Demirel University Faculty of \\ Medicine, Isparta, Turkey \\ ${ }^{2}$ Department of Pediatrics, Süleyman Demirel University Faculty of Medicine, Isparta, Turkey
}

\begin{abstract}
Aim: Foreign bodies ingested by the oral route enter into the gastrointestinal tract and are considered a significant health problem in the childhood. In this study, we evaluated the pediatric patients who presented to our hospital with the complaint of ingestion of foreign body.

Material and Methods: The hospital records of all children who presented to our clinic because of ingestion of foreign body between January 2008 and January 2015 were examined retrospectively. The complaints at admission, the types of foreign bodies ingested, the localization of the foreign body in the gastrointestinal tract and the approaches and treatment methods used were examined.

Results: Thirty-six (56\%) of 64 patients included in the study were male and 28 (44\%) were female and the mean age was $5.7 \pm 4.6$ years (10 months-17 years). Thirty eight (59\%) of 64 children who were included in the assessment were below the age of five years. The most common complaint at presentation was parental recognition of the ingested object and dysphagia. The most commonly ingested foreign bodies included coins, sewing pins, safety pins and hairclips. Nail clipper detected in the stomach, sewing pin which penetrated through the duodenal wall and stuck to hepatic parenchyma were the first pediatric cases in the literature. Upper esophagus was the most common location for foreign bodies. Endoscopic examinations were performed in 55 of 64 children.

Conclusions: Early detection and treatment of ingested foreign bodies in the upper gastrointestinal system is important in terms of preventing possible complications. In our study, the most frequent foreign bodies detected in the upper digestive tract were coins and they were most frequently detected in the upper esophagus. Most of our patients were below the age of five years. Flexible endoscopic method was used commonly for treatment. (Turk Pediatri Ars 2015; 50: 234-40)
\end{abstract}

Keywords: Children, endoscopy, gastrointestinal tract, foreign body ingestion

\section{Introduction}

Intake of foreign body into the gastrointestinal system (GIS) by the oral route is a significant problem in the childhood (1). Although ingestion of foreign body can be observed at any age, it occurs more frequently in children aged between six months and five years who tend to recognize objects found around them by delivering them to their mouths $(1,2)$.

Foreign bodies taken by the oral route lead to severe morbidity and mortality by entering into the respiratory and gastrointestinal systems. Therefore, these cases should be evalauated urgently (3-6). The most common foreign bodies ingested by children include coins, toys, magnets and batteries, though they vary according to the traditions and nutritional habits of populations $(7,8)$. While ingestion of fish bone is observed as a regional problem in the countries in Far East Asia, cases of ingestion of safety pin constitute a seperate group in our country (9-13).

While foreign bodies with a soft end do not constitute a problem, the ones with sharp edges lead to serious problems (3).
Most foreign bodies (80\%) pass the gastrointestinal tract easily and $20 \%$ are stuck in the anatomical transition regions of the GIS (5). The regions of anatomic obstruction include the upper, medium and lower obstructions of the esophagus, pylorus, ileocecal valve and rectosigmoid colon (14). Sometimes, stenosis related with webs, rings, malignancy and eosinophilic esophagitis in the esophagus may lead to obstruction in the gastrointestinal system even after daily meals imitating foreign body (14-16). Initiation of use of endoscopic interventions in the childhood allows the possibility of removing the objects ingested by non-surgical methods. Endoscopic method is used with a rate of $10-20 \%$ and surgical intervention is required with a rate lower than $1 \%(17,18)$.

In this study, we aimed to retrospectively evaluate our pediatric patients who presented to our hospital with a complaint of ingestion of foreign body.

\section{Material and Methods}

The hospital files of all children who presented to Süleyman Demirel University, Department of Pediatrics with a 
complaint of ingestion of foreign body between January 2008 and January 2015 were examined retrospectively. The age, gender, time of presentation, type of ingested object, complaints and findings at the time of presentation, location of the foreing body and treatment approach preferred were evaluated by examining the hospital files.

All children who presented to our clinic with a complaint of ingestion of foreign body were evaluated by plain films involving the GIS from the mouth up to the anus. The patients who were found to have foreign body in the esophagus were internalized and these foreign bodies were removed by flexible endoscopy. In addition, endoscopy was performed urgently in cases of ingestion of foreign bodies with sharp edges and foreign bodies containing chemical substances (for example: battery). If the foreign body ingested had passed the esophagogastric junction and was asymptomatic, the patient was followed up clinically. All asymptomatic patients who had foreign bodies in the stomach and intestines were followed up by X-rays. The foreign bodies which were found to be dislocated on radiography were followed up for three weeks. In the follow-up, the option of surgical intervention was considered as a possibility.

When it was decided to perform endoscopy, the procedure was realized only when it was assured that the child had an empty stomach in the last 2-4 hours or after a fourhour fasting. The procedure was performed in the operation room under general anesthesia in all children below the age of five who ingested foreign body. In our patients aged above ten years who did not require operation room conditions, endoscopy was performed by applying topical anethesia in the pharyngeal region (Xylocaine spray) or by administering midazolam $(0.1 \mathrm{mg} / \mathrm{kg})$ and ketamine $(1 \mathrm{mg} / \mathrm{kg}$ ) intravenously. Heart rate and oxygen saturation values were monitored in all patients during the procedure. Pentax EG $2470 \mathrm{~K}$ video endoscopy device was used in all patients for endoscopy. Snare, basket, hazelnut mouth forceps, V-sahped forceps, tripod forceps and biopsy forceps were used to remove foreign bodies. After the foreign body was removed, reevaluation was performed by endoscopy in terms of complications including mucosal erosion and perforation. All children who underwent endoscopy were followed up for 2-4 hours after the anesthesia and procedure because of the risk of complications.

Ethics committee approval was obtained with the decision of Süleyman Demirel University Clinical Researches Ethics Committee (date: 09.07.2015, number: 153). Verbal and written consent was obtained from the parents of all children who underwent the procedure.

\section{Statistical analysis}

The data were assessed using complementary-descriptive statistical method. The categorical variables were expressed as percentage (\%) values.

\section{Results}

It was found that a total of 64 children presented to Süleyman Demirel University, Department of Pediatrics with a complaint of ingestion of foreign body between January 2008 and January 2015. Thirty six of these patients were male (56\%) and 28 (44\%) were female. The mean age was $5.7 \pm 4.6$ years ( 10 months- 17 years). Thirty eight $(59 \%)$ of 64 children who were included in the assessment were below the age of five years. The distribution of the patients by age and gender is summarized in Table 1. Among the complaints at presentation, recognition of ingestion of foreign body by the parents $(24,37 \%)$ and difficulty in swallowing $(24,37 \%)$ were in the first order. Other complaints included cough $(8,12 \%)$, a sensation of something being stuck in the throat when swallowing $(6,9 \%)$, vomiting $(3,5 \%)$, salivation, stomach ache and vomiting blood (2, 3\%). Respiratıory difficulty or cyanosis did not develop in any child (Table 2). No psychiatric disorder was found in any child who presented with a complaint of ingestion of foreing body.

Forty three (67\%) of the patients presented in hospital in the first 24 hours, 17 (27\%) presented in 24-72 hours and three $(5 \%)$ presented after the $72^{\text {nd }}$ hour. A patient aged five years who ingested a pin presented to our center after three months. Thrity nine (61\%) of the children who presented in our hospital with a complaint of ingestion of foreing body presented in our emergency department and the other 25 children were referred to our center from other healthcare facilities for endoscopy.

Plain film was obtained in all cases to determine the location of the foreign body in the gastrointestinal tract and whether or not perforation occured in the GIS. Afterwards, endoscopic procedure was planned according to the level and composition (if it had a sharp edge or if it contained

Table 1. Distribution of the subjects by age and gender

\begin{tabular}{lccc}
\hline Age range (years) & \multicolumn{2}{c}{ Gender } & Total \\
\hline & Female & Male & \\
& $\mathrm{n}(\%)$ & $\mathrm{n}(\%)$ & $\mathrm{n}(\%)$ \\
6 months - 5 years & $16(42)$ & $22(58)$ & $38(59)$ \\
5-10 years & $7(41)$ & $10(59)$ & $17(26)$ \\
11-18 years & $5(55)$ & $4(45)$ & $9(15)$ \\
Total & $28(44)$ & $36(56)$ & $64(100)$ \\
\hline
\end{tabular}


Table 2. Complaints of the subjects at presentation

\begin{tabular}{lc}
\hline Complaint & $\mathbf{n}(\%)$ \\
\hline Dysphagia & $24(37)$ \\
Recognition by the family & $24(37)$ \\
Cough & $8(12)$ \\
A sensation of something being stuck in the throat & $6(9)$ \\
Vomiting & $3(5)$ \\
Drooling, gastric pain, vomiting blood & $2(3)$ \\
\hline
\end{tabular}

Table 3. Foreign bodies ingested

\begin{tabular}{lc}
\hline Foreign body & $\mathbf{n}(\%)$ \\
\hline Coin & $25(37)$ \\
Pin & $5(8)$ \\
Safety pin & $5(8)$ \\
Hair pin & $4(6)$ \\
Marble & $2(3)$ \\
Fish bone & $2(3)$ \\
\hline Other: Bezoar, bush, tea spoon, iron wire, button, & 1 of each \\
plum seed, gelatine, token, apricot seed, bone, & \\
red meat, bracelet, earring, metal zipper, battery & \\
terminal, battery, chicken meat, nail clipper, \\
water-swellable toy, food waste, ring.
\end{tabular}

Table 4. Distribution of the foreign bodies by age range

\begin{tabular}{lccc}
\hline Foreign body & $\begin{array}{c}\mathbf{6} \text { months-5 years } \\
\mathbf{n}\end{array}$ & $\begin{array}{c}\mathbf{6 - 1 0} \text { years } \\
\mathbf{n}\end{array}$ & $\begin{array}{c}\mathbf{1 1 - 1 8} \text { years } \\
\mathbf{n}\end{array}$ \\
\hline Coin & 18 & 7 & - \\
Safety pin & 4 & 1 & - \\
Pin & 3 & - & 2 \\
Hair pin & 3 & 1 & - \\
Marble & 1 & 1 & - \\
Fish bone & - & 1 & 1 \\
Other & 9 & 6 & 6 \\
\hline
\end{tabular}

any chemical substance including battery) of the foreing body and the child's clinical status and endoscopic examination was performed in 55 (85\%) of the children. Most frequent foreing bodies included coins ( 25 cases), pins (five cases), safety pins (five cases) and hair pins (four cases) (Table 3). All children who ingested a coin were below the age of ten years and especially the group below the age of five years contituted the majority (72\%). Similarly, all children who ingested a safety pin were below the age of ten years and the group below the age of five years contituted the majority (80\%). Sixty percent of the children who ingested a pin were below the age of five years and $40 \%$ were above the age of ten years (Table 4) (Figure 1-3).

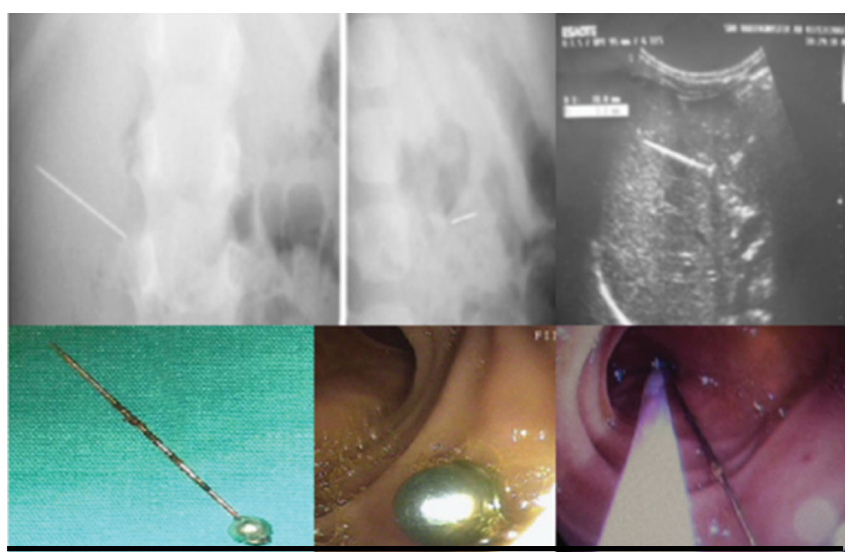

Figure 1. Pin which penetrated through the duodenal wall and stuck to the hepatic parenchyma

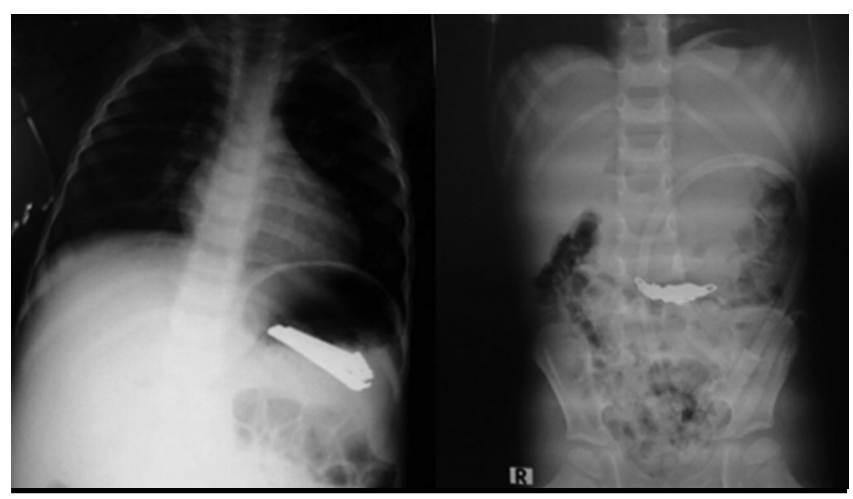

Figure 2. Nail clipper in the stomach and bracelet in the duodenum

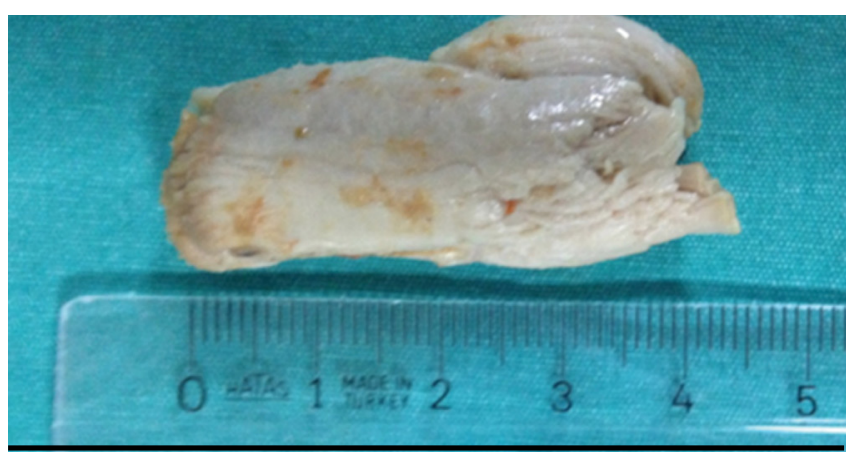

Figure 3. Chicken meat removed from the esophagus

When the locations of the foreing bodies were examined by endoscopic examination and radiographies, it was found that they were most frequently found in the upper part of the esophagus (26 patients), stomach (10 patients), middle part of the esophagus (eight patients), duodenum (four patients), lower part of the esophagus (two patients) and right tonsil (one patient) (Table 5).

Endoscopic examination was performed in the operation room under general anesthesia in 45 (82\%) of 55 children according to age and the status of the foreign body. The procedure was performed after intravenous administration of midazolam $(0.1 \mathrm{mg} / \mathrm{kg})$ and ketamine $(1 \mathrm{mg} / \mathrm{kg})$ in five patients (14\%) who were aged above 11 years. In 
Table 5. Distribution of the foreign bodies by anatomic region

\begin{tabular}{lc}
\hline Anatomic region & (n) \\
\hline Upper esophagus & 26 \\
Mid-esophagus & 8 \\
Lower esophagus & 2 \\
Stomach & 10 \\
Duodenum & 4 \\
Right tonsil & 1 \\
Undefined & 13 \\
\hline
\end{tabular}

addition, topical anethesia was performed with Xylocain spray in the pharyngeal region in two children (4\%) aged above 11 years.

The most common foreign body removed from the upper part of the esophagus where foreign bodies are found most frequently was coin (68\%). Seventhy two percent of the patients were aged below five years and foreign body ingestion occured as a result of accidental ingestion during playing. The other foreign bodies found in this region included hair pins (8\%), marbles (4\%), iron wires (4\%), battery lead terminals (4\%), safety pins (4\%), buttons (4\%), bones (4\%) and rings (4\%). Endoscopy was performed under general anesthesia for all foreign bodies in this reigon and the foreign bodies were removed using snare, basket, tripod and hazelnut mouth forceps.

It was found that the foreing bodies removed from the stomach which is the second most common region where foreing bodies are found were mostly coins (30\%) and they were followed by pins $(20 \%)$, safety pins $(10 \%)$, batteries $(10 \%)$, marbels (10\%), nail clippers (10\%), hair pins (10\%) and bushes (10\%). Nine (90\%) of 10 children who were found to have foreign body in their stomach were aged between six and 10 years. Endoscopic examination was performed under general anesthesia in all of these children. Excluding the case of hair pin where the foreing body was forced to be removed from the antrum and the procedure was discontinued because of perforation risk, the foreign bodies were removed using snare, basket, tripod and hazelnut mouth forceps.

Two subjects who were found to have bracelets and one subject who was found to have a safety pin in the duodenum by plain films were followed up clinically without endoscopic examination, since it was difficult to reach the foreing body by endoscopy in these cases. In the follow-up, it was found that these foreign bodies left the body in 48-72 hours without causing any problem. One patient who ingested a pin presented to another center two days after the incident and the pin was found to be located in the right upper quadrant on radiography. This patient was decided to be followed up, because he had no complaint. He was referred to our center after three months when it was observed that the position of the pin remained unchanged on radiography. As a result of the examinations performed in our hospital, it was found that the ball-like part of the pin was in the duodenum and the end part was in the hepatic parenchyma. The pin was removed by way of flexible endoscopy without any problem.

The foreign bodies in the other anatomic regions showed variable object and age distribution. These foreing bodies were removed by endoscopy using general anestesia, intravenous midazolam-ketamine administration or topical Xylocain in these children.

\section{Discussion}

Although ingestion of foreign body may be observed at any age, it is more frequently observed in infants who tend to recognize objects found around them by delivering them to their mouths and in play age children who tend to ingest objects accidentally (2). Most foreign bodies ingested leave the body spontaneously after passing the GIS without leading to any mortality or morbidity $(18,19)$. In the literature, it has been reported that $40 \%$ of the cases of ingestion of foreign body occur without the recognition of the parents. Therefore, it is thought that the number of cases of ingestion of foreign body in the childhood is higher compared to the number reported (20).

In this article, 64 patients who presented to our clinic with a complaint of foreign body ingestion were presented and discussed. In previous studies, it was reported that patients presented in the first 10 hours (90\%) after ingestion of foreign body $(21,22)$. As the presentation time gets longer, the rates of complications increase (23). It was found that $43(67 \%)$ of 64 patients in our study presented in the first 24 hours and no complication occured.

In the literature, the complaints at the time of first presentation of children who have ingested foreing body include a sensation of something being stuck in the gastrointestinal system, salivation, cough, vomiting, bloody saliva, refusal of food, pain (in the neck, chest or abdomen) and respiratory distress (22). In our study, the complaints at the time of first presentation included dysphagia (37\%), cough (12\%), a sensation of something being stuck in the throat (9\%), vomiting (5\%) and bloody saliva (3\%) in order of frequency.

Although the foreing bodies ingested vary by country and regions, coins, toys, magnets and batteries are generally in the first order $(7,8)$. In one study conducted in Chi- 
na with 1265 children and in another study conducted in Belgium with 325 children, the rates of ingestion of coin were found to be $47 \%$ and $27 \%$, respectively $(24,25)$. In our study, coin was in the first order in the children who presented with a complaint of foreign body ingestion and this was followed by pins $(5 / 64,7 \%)$, safety pins $(5 / 64,7 \%)$, hair pins $(4 / 64,6 \%)$ and other objects $(26 / 64,43 \%)$. In our study, coin was the most common foreing body ingested and this was compatible with the literature.

In the study conducted by Aydoğdu et al. (11) in Turkey in which 176 children who ingested foreign body were evaluated, the first two agents were found to be safety pin (36\%) and pin (27\%) (11). In our study, these both agents were in the second order with a rate of $7 \%$. Similar to the study of Aydoğdu et al. (11), ingestion of safety pin was more frequent in children aged below two years. Again, similar to the results of the same study, a portion (40\%) of the subjects who ingested pins was constituted from adolescent girls above the age of 10 years who covered their heads. The reason for this has been reported to be accidental ingestion related with deep inhalation or laughing while using pins with the aim of combining the ends of scarf. Again similarly, pins were found in three patients (60\%) aged below the age of five years in our study. The reason of this was thought to be accidental ingestion of pins which were attached to baby dresses with different purposes.

When the locations of the foreign bodies in the GIS were examined, it was found that the esophagus (36/64, 53\%) and especially the upper part of the esophagus (26/64, $40 \%)$ were in the first order. In many studies, the most commonly reported region in terms of stuck foreign body is the upper anatomical region which is also known as cervical esophagus $(25,26)$. The importance of esophagus is the fact that foreing bodies like coins which cause compression may lead to necrosis after 4-5 hours (27). In the literature, coins have been reported to be the most common foreing body in the esophagus $(15,28)$. In our study, the most common foreing body found in the esophagus was reported to be coin $(22 / 36 ; 61 \%)$ compatible with the literature. In a study conducted in Hong Kong region in China which has a different culture, it was reported that bones were found in the esophagus with a rate of $85 \%$ and $60 \%$ of these bones were fish bone (29). In our study, two fish bones, one bone and one piece of chicken meat were removed from esophagus. In our series, these cases were thought to occur as a result of rapid eating of fish and meat, though such cases of foreign body ingestion are not as frequent in our country as in Far East countries.

The second most common localization of foreing bodies was the stomach. Among the foreign bodies found in the stomach, coins were in the first order (30\%). All foreign bodies were removed by endoscopy except for the hair pin found in the stomach. A nail clipper was removed from the stomach of a four-year old girl under endoscopic guidance (Figure 3). No case of ingestion of nail clipper was found in the literature search. Two patients in whom nail clippers were removed from the urethra and left main bronchus were reported in the literature (30, 31). A foreign body which may constitute a threat in the stomach and GIS is battery. The reason for this is the fact that batteries which are alkaline lead to local erosion in the mucosa of the GIS and sometimes to findings of systemic intoxication $(8,22)$. In our series, there was only one case of battery ingestion; the battery was found in the stomach and was removed under endoscopic guidance four hours after ingestion.

Foreign bodies found in the duodenum generally leave the GIS without causing to any problem $(8,22,23)$. In our study, four of the foreign bodies were found to be in the duedonum. Our five-year old patient who ingested a pin was referred to our center three months later and the pin was removed from the duodenum by endoscopic method (32). It was found that the other foreign bodies in the duodenum left the GIS without any problem.

Endoscopy was performed in 55 (86\%) of 64 children who presented with a complaint of foreign body ingestion. Anesthesia is applied in most children during endoscopy procedure. In adults, mild sedation is usually sufficient during endoscopic procedure. However, the procedure is ideally performed by endotracheal intubation under general anesthesia to fully protect the airway in the childhood (18). In our study, the procedure was performed in operation room under general anesthesia after intubation in all children (82\%) aged below 10 years. In the older age group, endoscopy was performed using intravenous midazolam-ketamine in eight patients (14\%) and topical Xylocain spray in the pharyngeal region in two patients (4\%).

The rate of use of endoscopy to remove foreign bodies has been reported to be $34 \%$ in our country by Aydoğdu et al. (11), $25 \%$ in Belgium and $80-90 \%$ in China and Korea $(23,24)$. It was thought that the high rate of use of endoscopy (85\%) in our country like Far East countries including China and Korea was related with the anxiety of the parents and their demand for the foreign body to be removed immediately. Although there are centers using different techniques and assitive devices to remove foreign bodies, the most commonly used method is endoscopy and the most common assistive devices are forceps, snare and basket $(23,33)$. In our study, forceps, snare and basket were also used similarly during endoscopies performed in our clinic. Surgical intervention was 
not needed in any of our cases of foreign body ingestion and no complication occured.

In conclusion, foreing body ingestion is a significant public health problem especially in children aged below five years. According to our results, the most common foreign body found in the upper gastrointestinal system was coin and the most common localization of foreing bodies was the upper part of the esophagus. Flexible endoscopy was frequently used in treatment. The endoscopic procedure was performed in the operation room under general anesthesia below the age of 10 years and in the endoscopy unit using intravenous anesthesia or topical anesthesia in the pharyngeal region. No complication occured. Parents should be educated and precautions should be taken in places where children play in order to prevent cases of foreign body ingestion and more serious problems which may develop in relation.

Ethics Committee Approval: Ethics committee approval was received for this study from the ethics committee of Süleyman Demirel University Faculty of Medicine Clinical Studies Ethical Committee (09.07.2015 date/153).

Informed Consent: Written and verbal informed consent was obtained from patients' parents who participated in this study.

Peer-review: Externally peer-reviewed.

Author Contributions: Concept - M.A.; Design - F.S.; Supervision - M.A.; Data Collection and/or Processing - F.S.; Analysis and/or Interpretation - T.K.; Literature Review - S.D.; Writing - S.D.; Critical Review - T.K.

Acknowledgement: We would like to thank to the endoscopy unit for their devoted work.

Conflict of Interest: No conflict of interest was declared by the authors.

Financial Disclosure: The authors declared that this study has received no financial support.

\section{References}

1. Demirören K, Dülger AC, Ölmez Ş, ve ark. Üst gastrointestinal sistem yabancı cisimleri olan çocuklarda fleksibl endoskopik işlem. Dicle Tip Dergisi 2014; 41: 205-9. [CrossRef]

2. Kaya F, Çiftçi İ, Seçkin AN. Çocuklarda yabancı cisim yutulmayı nadir bir yöntemle çlkartma. Selçuk Tıp Dergisi 2014; 30: 79-81.

3. Wright CC, Closson FT. Updates in pediatric gastrointestinal foreign bodies. Pediatr Clin North Am 2013; 60: 1221-39. [CrossRef]

4. Uyemura MC. Foreign body ingestion in children. Am Fam Physician 2005; 72: 287-91.

5. Gregori D, Scarinzi C, Morra B, et al. ESFBI Study Group. Ingested foreign bodies causing complications and requi- ring hospitalization in European children: results from the ESFBI study. Pediatr Int 2010; 52: 26-32. [CrossRef]

6. Walker WA, Goulet O, Kleinman RE, Sherman PM, Shneider BL, Sanderson IR. Pediatric Gastrointestinal disease. 4th ed. Ontario: BC Decker; 2004. p. 1691-2.

7. Kay M, Wyllie R. Pediatric foreign bodies and their management. Curr Gastroenterol Rep 2005; 7: 212-8. [CrossRef]

8. Waltzman ML, Baskin M, Wypij D, Mooney D, Jones D, Fleisher G. A randomized clinical trial of the management of esophageal coins in children. Pediatrics 2005; 116: 614-9. [CrossRef]

9. Tiryaki T, Doğancı T, Livanelioğlu Z, Atayurt H. Çocukluk çağında yabancı cisim yutulması. Turkiye Klinkleri Pediatr 2004; 13: 67-70.

10. Yalçin S, Karnak I, Ciftci AO, Senocak ME, Tanyel FC, Büyükpamukçu N. Foreign body ingestion in children: an analysis of pediatric surgical practise. Pediatr Surg Int 2007; 23: 755-61. [CrossRef]

11. Aydoğdu S, Arikan C, Cakir M, ve ark. Foreign body ingestion in Turkish children. Turk J Pediatr 2009; 51: 127 32.

12. Wong KK, Fang CX, Tam PK. Selective upper endoscopy for foreign body ingestion in children:an evaluation of management protocol after 282 cases. J Pediatr Surg 2006; 41: 2016-8. [CrossRef]

13. Gün F, Salman T, Abbasoglu L, Celik R, Celik A. Safetypin ingestion in children: a cultural fact. Pediat Surg Int 2003; 19: 482-4. [CrossRef]

14. Schwartz GF, Polsky HS. Ingested foreign bodies of the gastrointestinal tract. Am Surg 1976; 42: 236-8.

15. Smith MT, Wong RK. Foreign bodies. Gastrointest Endosc Clin N Am 2007; 17: 361-482. [CrossRef]

16. Balci AE, Eren S, Eren MN. Esophageal foreign bodies under cricopharyngeal level in children: an analysis of 1116 cases. Interact Cardiovasc Thorac Surg 2004; 3: 148. [CrossRef]

17. Kay $M, W y l l i e ~ R$. Techniques of foreign body removal in infants and childeren. Tech Gastrointest Endosc 2002; 4: 188-95. [CrossRef]

18. Sugawa C, Ono H, Taleb M, Lucas EC. Endoscopic management of foreign bodies in the upper gastrointestinal tract: A review. World J Gastrointest Endosc 2014; 16: 475-81. [CrossRef]

19. Çiftçi A, Bingöl-Koloğlu M, Şenocak ME, Tanyel FC, Büyükpamukçu N. Bronchoscopy For Evaluation Of Foreign Body Aspiration in Children. J Ped Surg 2003; 38: 1170-6. [CrossRef]

20. Wright CC, Closson FT. Updates in pediatric gastrointestinal foreign bodies. Pediatr Clin North Am 2013; 60: 1221-39. [CrossRef]

21. İnci İ, Özçelik C, UUlkü R, Eren N. Özofagus yabancı cisimleri: 682 olgunun incelenmesi. GKDC Dergisi 1999; 7: 148-152. 
22. Kruk-Zagajewska A, Szmeja Z, Wojtowicz J, Wierzbicka M, Piatkowski K. Foreign bodies in the esophagus. Otolaryngol Pol 1999; 53: 283-8.

23. Arana A, Hauser B, Hachimi-Idrissi S, Vandenplas Y. Management of ingested foreign bodies in childhood and review of the literature. Eur J Pediatr 2001; 160: 468-72. [CrossRef]

24. Ucan ES, Tahaoglu K, Mogolkoc N, et al. Turban pin aspiration syndrome: a new form of foreign body aspiration. Respir Med 1996; 90: 427-8. [CrossRef]

25. Little DC, Shah SR, St Peter SD, et al. Esophageal foreign bodies in the pediatric population: our first 500 cases. J Pediatr Surg 2006; 41: 914-8. [CrossRef]

26. Lin $\mathrm{HH}$, Lee SC, Chu HC, Chang WK, Chao YC, Hsieh TY. Emergency endoscopic management of dietary foreign bodies in the esophagus. Am J Emerg Med 2007; 25: 662-5. [CrossRef]

27. Gershman G, Ament M. Practical pediatric gastrointestinal endoscopy. Massachusetts: Blackwell Publishing; 2007. p. 105-9.
28. Dokler ML, Bradshaw J, Mollitt DL, Tepas JJ 3rd. Selective management of pediatric esophageal foreign bodies. Am Surg 1995; 61: 132-4.

29. Nandi $P$, Ong B. Foreign body in the esophagus: rewiew of 2394 cases. Br J Surg 1978; 65: 5-9. [CrossRef]

30. Gorur R, Kunter E, Isitmangil T, et al. Medical image. Cough and wheeze. Nail clippers in the left main bronchus. $\mathrm{N} \mathrm{Z}$ Med J 2007; 9: 120: U2802.

31. Hatipoglu N, Yucel M, Hatipoglu N, Yentur S, Semercioz A. An unusual foreign body in urethra: nail clippers. Cent European J Urol 2011; 64: 92-3. [CrossRef]

32. Akçam M, Koçkar C, Tola HT, Duman L, Gündüz M. Endoscopic removal of an ingested pin migrated into the liver and affixed by its head to the duodenum. Gastrointest Endosc 2009; 69: 382-4. [CrossRef]

33. Karaman A, Cavusoglu YH, Karaman I, Erdogan D, Aslan MK, Cakmak O. Magill forceps technique for removal of safety pins in upper esophagus: a preliminary report. Int J Pediatr Otorhinolaryngol 2004; 68: 1189-91. [CrossRef] 